\title{
Avaliação do turismo de observação de botos- cinza na Reserva Faunística Costeira de Tibau do Sul (Refauts), Rio Grande do Norte, Brasil
}

\author{
An assessment of the guiana dolphin watching tourism \\ activities at the Coastal Wildlife Reserve of Tibau do \\ Sul (Refauts), Rio Grande do Norte State, Brazil
}

Diana Gonçalves Lunardi ${ }^{a}$ Josivânia Emanuelly Azevedo dos Santos ${ }^{b}$ Larycynthia Luana Sousa do Nascimento ${ }^{c}$

Diana Carvalho de Freitas ${ }^{d}$

Vitor de Oliveira Lunardie

a Universidade Federal Rural do Semiárido (Ufersa), Mossoró, RN, Brasil End. Eletrônico: lunardi.diana@ufersa.edu.br

${ }^{b}$ Universidade Federal Rural do Semiárido (Ufersa), Mossoró, RN, Brasil End. Eletrônico: emanuelly.josivania@gmail.com

'Universidade Federal Rural do Semiárido (Ufersa), Mossoró, RN, Brasil End. Eletrônico: larycynthiasousa@gmail.com

¿Universidade Federal Rural do Semiárido (Ufersa), Mossoró, RN, Brasil End.Eletrônico:dcrvfreitas@gmail.com

eUniversidade Federal Rural do Semiárido (Ufersa), Mossoró, RN, Brasil End.Eletrônico: lunardi.vitor@ufersa.edu.br

doi:10.18472/SustDeb.v8n1.2017.20213

Recebido em 07.11.2016

Aceito em 06.04.2017

ARTIGO - VARIA

\section{RESUMO}

O turismo de observação de cetáceos (TOC) pode contribuir para a conservação destes e para o desenvolvimento econômico local. Este estudo teve como objetivo avaliar o turismo de observação de botos-cinza, de forma a subsidiar o plano de manejo da Reserva Faunística Costeira de Tibau do Sul (Refauts). Durante as expedições à área de estudo, foram realizadas entrevistas com mestres de embarcação, censos e vistorias nas embarcações licenciadas e registro do fluxo do TOC. Foram registradas 11 embarcações licenciadas operando na Refauts, 368 passeios durante 16 dias de amostragem e um total de 4.717 turistas. Verificou-se, em $30 \%$ dos registros, que os mestres de embarcação não costumam cumprir a determinação prevista em lei quanto à limitação do número de barcos nas enseadas. Ainda sobre os resultados, vale mencionar que o TOC na Refauts vem desempenhando um papel importante na economia local, contudo é preciso que um plano de ação seja implantado, para assegurar a conservação do boto-cinza na Reserva.

Palavras-chave: Boto-cinza. Conservação. Ecoturismo. Reserva Faunística Costeira de Tibau do Sul. Turismo de Observação de Golfinhos. 


\section{ABSTRACT}

Dolphin watching touristic activities can contribute both to the conservation of dolphins and to the development of the local economy. As a part of the management plan of the Coastal Wildlife Reserve of Tibau do Sul (Refauts), the present study aimed to evaluate Guiana dolphin watching activities. During the expeditions to the study area, interviews were conducted among boat drivers. The research also included censuses and inspections of licensed tourism boats, as well as a record of the dolphin watching touristic flow. Within a sample of 16 days of observation, a total of 11 licensed tourism boats operating in Refauts was registered, along with 368 observation tours and a 4,717 tourists. Results showed that in $30 \%$ of the registries - boat drivers did not comply with the legal determinations for the Refauts area, which limit the number of boats operating in the bays. Results also show that Guiana dolphin watching activities in Refauts have played an important role in the development of the local economy, but an action plan is still necessary in order to ensure the conservation of Guiana dolphins in Refauts.

Keywords: Guiana Dolphin. Conservation. Ecotourism. Coastal Wildlife Reserve of Tibau do Sul. Dolphin Watching.

\section{INTRODUÇÃO}

O ecoturismo ou turismo ecológico provavelmente surgiu na década de 1980, como resultado de uma globalização dos problemas ambientais e consequente disseminação da necessidade de práticas conservacionistas (DIAMANTIS, 1999). Embora haja pouco consenso sobre sua definição (GOODWIN, 1996), significações mais amplas de ecoturismo incluem a prática turística realizada em ambientes naturais ou parcialmente naturais, que esteja em conformidade com a conservação da biodiversidade e com o desenvolvimento sustentável das populações humanas locais (TORQUEBIAU; TAYLOR, 2009).

O ecoturismo pode beneficiar as áreas protegidas de três formas: (i) diretamente, por meio da renda obtida com a venda de ingressos, reinvestindo o valor arrecadado na conservação de habitats e espécies; (ii) indiretamente, incluindo a comunidade local no processo de geração de renda, por exemplo, a partir das visitas guiadas, hospedagem dos turistas e comercialização de alimentos, tornando a comunidade uma aliada na conservação da área protegida e (iii) por meio da informação ambiental e sensibilização dos turistas para as necessidades de conservação da biodiversidade (GOODWIN, 1996).

As Unidades de Conservação podem ser importantes promotoras do ecoturismo (AGARDY, 1993) - a exemplo do turismo de observação de cetáceos (TOC) - promovendo a conservação da diversidade biológica e favorecendo a manutenção de espécies, populações e ecossistemas naturais (CARREGOSA et al., 2015).

O turismo de observação de cetáceos é uma atividade que envolve a observação de baleias, golfinhos e/ou toninhas em seu ambiente natural, por meio de embarcações, pequenas aeronaves ou mesmo a partir de terra, na costa do mar (HOYT, 2001). Essa atividade altamente rentável, quando realizada de forma ordenada, pode contribuir para a conservação de cetáceos, para o desenvolvimento econômico local (CISNEROS-MONTEMAYOR et al., 2010; WILSON; TISDELL, 2003) e para a sensibilização dos turistas envolvidos no TOC (LÜCK, 2015).

Na América Latina, o TOC tem crescido substancialmente desde 1998, com uma taxa de crescimento de aproximadamente $11,3 \%$ ao ano, taxa três vezes maior do que a taxa mundial (HOYT; IÑíGUEZ, 2008). 0 turismo de observação de cetáceos na América Latina parece atrair pelo menos 880 mil turistas ao ano e movimentar cerca de 79 milhões de dólares apenas com a venda de ingressos. Somente na América Latina, cerca de 20 países realizam o TOC, incluindo países como o Brasil, México, Peru, Argentina e Chile (HOYT; IÑíGUEZ, 2008).

No Brasil, o TOC parece ter se iniciado na década de 1980, com a observação do golfinho-rotador (Stenella longirostris) no Parque Nacional Marinho de Fernando de Noronha (HOYT; IÑÍGUEZ, 2008). Hoje existem pelo menos outros sete importantes destinos para observação de cetáceos no Brasil: Parque Nacional de Anavilhanas, AM, para observação do boto-da-Amazônia (Inia geoffrensis), Parque Nacional dos Abrolhos e Área de Proteção Ambiental da Plataforma Continental do Litoral Norte, BA, para observação de baleia-jubarte (Megaptera novaeangliae), Área de Proteção Ambiental da baleia-franca, SC, para observação de baleia-franca (Eubalaena australis) e de boto-da-tainha (Tursiops truncatus), Área de Proteção Ambiental de Cananeia-Iguape-Peruíbe, SP, Área de Proteção Ambiental de Anhatomirim, SC, e Reserva Faunística Costeira de Tibau do Sul (Refauts), RN, para observação de boto-cinza (Sotalia guianensis). 
O boto-cinza é uma das menores espécies da família Delphinidae (BARROS, 1991), possuindo ampla distribuição ao longo da costa atlântica tropical e subtropical da América do Sul e Central (BOROBIA et al., 1991; CARR; BONDE, 2000; FLORES, 1999). Trata-se de uma espécie gregária, com amplo repertório comportamental (LUNARDI; FERREIRA, 2014), que inclui complexas estratégias de forrageio, podendo variar de movimentos coordenados entre os membros do grupo até a utilização de saltos e batidas de caudal para contenção de presas (ROSSISANTOS; FLORES, 2009). O boto-cinza é frequentemente associado a baías, enseadas e estuários, onde as águas são mais rasas e protegidas das correntes marítimas e dos ventos fortes. Essa é provavelmente uma das razões que tornam o boto-cinza uma das principais espécies-alvo do TOC na costa do Brasil.

Na Refauts, praia de Pipa, o boto-cinza pode ser observado diariamente e tem sido estudado há pelo menos 22 anos, incluindo, por exemplo, a investigação de seu padrão comportamental (ARAÚJO et al., 2001; LUNARDI; FERREIRA, 2013; NASCIMENTO et al., 2008; SPINELLI et al., 2002), de sua dieta (PANSARD et al., 2011) e dos efeitos do turismo de observação sobre o comportamento desses animais (ALBUQUERQUE; SOUTO, 2013; CARRERA et al., 2008; VALLE; MELO, 2006). Por exemplo, Albuquerque e Souto (2013) sugeriram que o ruído do motor de uma embarcação é uma fonte potencial de perturbação que pode interferir na comunicação entre botoscinza, enquanto Carrera e colaboradores (2008) registraram redução no número de botos-cinza e de atividade de forrageamento na presença de barcos de turismo.

Embora a Refauts tenha sido criada em 2006, por meio do Decreto Municipal n. 14 (TIBAU DO SUL, 2006), com o intuito de proteger a biodiversidade costeira e marinha da região, em especial as tartarugas marinhas e o botocinza, ela ainda não dispõe de plano de manejo, o que vem dificultando a gestão adequada da Reserva. Em todo o Nordeste do Brasil, a Refauts, atualmente, é o principal destino para observação de botos-cinza, atraindo um número significativo de turistas brasileiros e estrangeiros durante todo o ano. Pode-se dizer, inclusive, que a atividade turística de observação de botos-cinza na Refauts tem sido uma das principais atividades responsáveis pela geração de emprego e renda na praia de Pipa, tendo em vista o crescente número de hotéis, restaurantes e lojas nas duas últimas décadas (CAMPOS; MAIA, 2015).

Contudo, apesar de sua relevante importância ecológica e econômica, o boto-cinza encontra-se vulnerável à extinção, segundo o Ministério do Meio Ambiente (ver Portarias MMA n. 444/2014 e n. 445/2014). Assim, tendo em vista a importância do TOC para a Refauts e para a economia local, este estudo tem como objetivo avaliar o turismo de observação de botos-cinza a partir de embarcação, por meio da: (i) descrição das embarcações licenciadas para o turismo de observação de botos-cinza; (ii) avaliação da frequência de passeios para observação de botos-cinza na Refauts; (iii) avaliação da conformidade das embarcações quanto à Lei Municipal n. 349/2007, que dispõe sobre o número máximo de embarcações na zona de uso restrito da Refauts e (iv) avaliação da rentabilidade do TOC na Reserva. A avaliação da atividade turística de observação de boto-cinza na Refauts poderá subsidiar um plano de manejo que contribua para a conservação dessa espécie ameaçada.

\section{MÉTODOS}

\section{1 ÁREA DE ESTUDO}

Este estudo foi realizado na Reserva Faunística Costeira de Tibau do Sul (Refauts), praia de Pipa (Figura 1), município de Tibau do Sul, estado do Rio Grande do Norte, Brasil. A região apresenta temperatura média anual de 26,4ㅡㅡ, precipitação média anual de $153 \mathrm{~mm}$ (INMET, 2015) e vegetação predominantemente composta por restinga herbácea (ALMEIDA JR.; ZICKEL, 2009). Quanto aos aspectos geológicos, a região apresenta formações rochosas de arenito e enseadas circundadas por dunas e falésias sedimentares que podem alcançar até $40 \mathrm{~m}$ de altura (PACHECO et al., 2006).

A Refauts (613'36,7" S; 353'36,7' W) foi criada em 2006, por meio do Decreto Municipal n. 14/2006, como uma Unidade de Conservação de uso sustentável. Sua criação teve como um dos principais objetivos a proteção do boto-cinza, Sotalia guianensis, e de tartarugas marinhas, especialmente a tartaruga-de-pente, Eretmochelys imbricata. O território da Refauts abrange o ambiente marinho e costeiro, apresentando três zonas: zona de uso restrito, zona de uso controlado e zona de amortecimento. A Refauts ocupa uma área de $555 \mathrm{~km}^{2}$, incluindo a enseada dos Golfinhos, a enseada do Madeiro e a praia de Cacimbinhas, e apresenta uma zona de amortecimento de $5.356 \mathrm{~km}^{2}$. As enseadas dos Golfinhos e do Madeiro fazem parte da zona de uso restrito da Reserva e são importantes áreas de concentração dos botos-cinza na Refauts. 

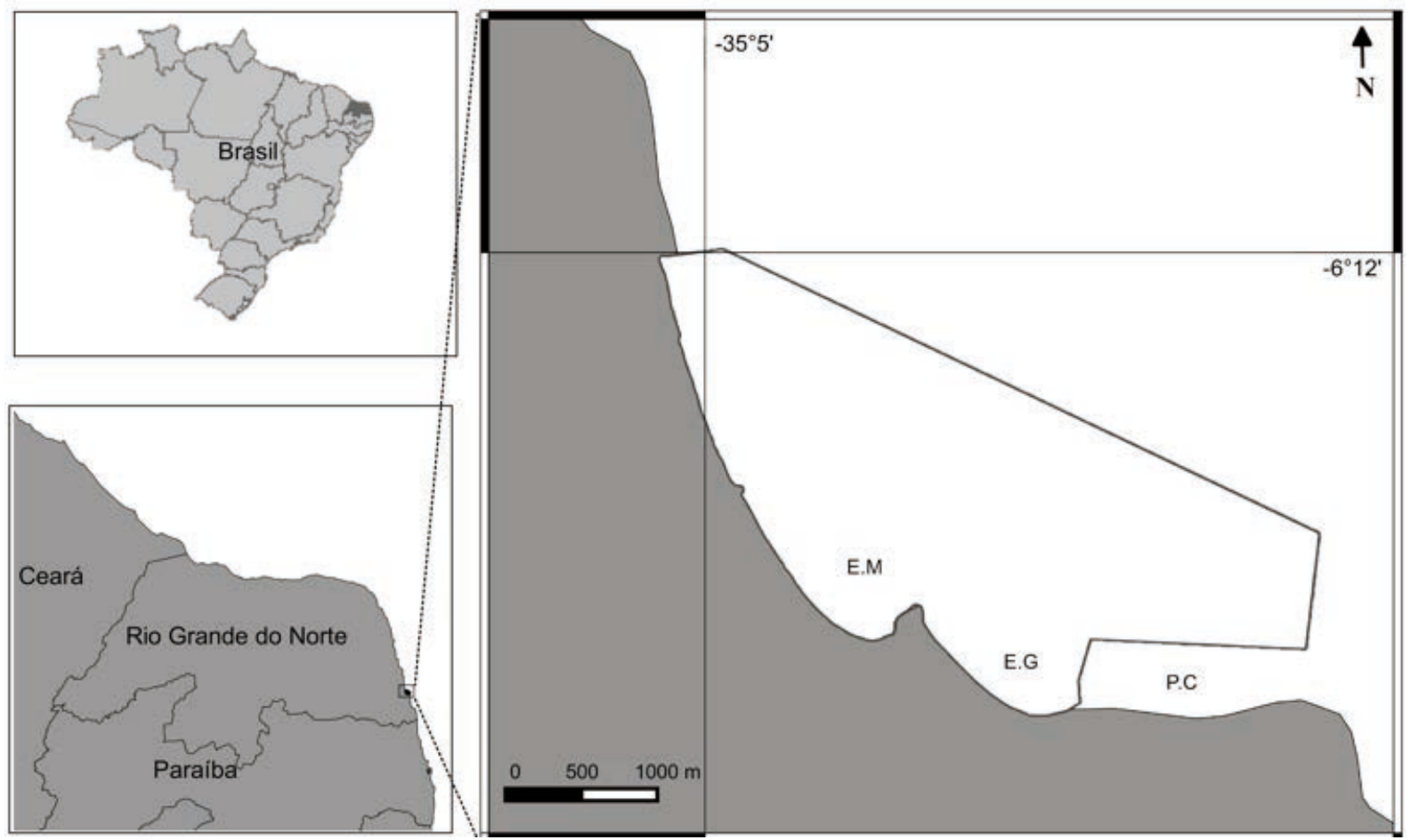

Figura 1 - Enseada do Madeiro e enseada dos Golfinhos, área de concentração de botos-cinza, Sotalia guianensis, na Reserva Faunística Costeira de Tibau do Sul (Refauts), localizada na praia de Pipa, município de Tibau do Sul, Rio Grande do Norte, Brasil. A região destacada em preto no mapa do Brasil mostra a localização do estado do Rio Grande do Norte.

Fonte: Os autores.

De acordo com a Lei Municipal n. 349/2007, que trata do transporte marítimo de visitação turística na Refauts, as embarcações turísticas e recreativas devem possuir Alvarás de Autorização emitidos pela Prefeitura Municipal de Tibau do Sul. Na zona de uso restrito é permitida a presença de apenas uma embarcação turística ou recreativa por vez, em cada uma das enseadas, com permanência de até 20 min (TIBAU DO SUL, 2007). Uma taxa de visitação turística por cada visitante embarcado vem sendo cobrada desde 2008 pela Prefeitura Municipal de Tibau do Sul. Embora esteja previsto em Lei que essa taxa turística seja destinada ao fomento à pesquisa, à manutenção da Refauts e à fiscalização das atividades na Reserva, ela ainda não tem sido destinada à maioria das atividades para a qual foi proposta.

\subsection{COLETA DE DADOS}

Para este estudo, foram realizadas quatro expedições à praia central de Pipa - local de saída e retorno das embarcações para observação de botos-cinza: uma primeira expedição em novembro de 2014 (3 dias), uma segunda expedição em março de 2015 (5 dias), uma terceira expedição em setembro de 2015 (7 dias) e uma quarta expedição em maio de 2016 (1 dia) - totalizando 16 dias de coleta de dados. Adicionalmente, foram realizadas três expedições às enseadas dos Golfinhos e do Madeiro - locais de maior concentração de botos-cinza na Refauts: uma primeira expedição em novembro de 2014 (2 dias), uma segunda expedição em março de 2015 (7 dias) e uma terceira expedição em setembro de 2015 (3 dias) - totalizando 12 dias de coleta simultânea de dados nessas duas enseadas. A duração das expedições variou de acordo com as condições favoráveis de tempo (como ausência de chuva) e disponibilidade de recurso financeiro para deslocamento e alojamento da equipe técnica. A coleta de dados ocorreu entre 09h e 16h, horário de início e término do TOC na Refauts, por uma equipe de no mínimo quatro pesquisadores previamente treinados. 
A coleta de dados foi dividida em quatro seções para atingir cada um dos quatro objetivos específicos deste estudo:

(i) Para a descrição das embarcações licenciadas para o turismo de observação de botos-cinza, foram realizadas vistorias e entrevistas com todos os 11 mestres de embarcação na área de estudo. As seguintes informações foram registradas: tipo de embarcação, ano de construção da embarcação, potência do motor e capacidade de passageiros por embarcação;

(ii) Para a avaliação da frequência de passeios para observação de botos-cinza na Refauts, foram registradas as seguintes informações: (a) horário de saída e retorno da embarcação à praia central de Pipa; (b) duração do passeio e (c) número total de passageiros por embarcação, especificando-se mulheres, homens e crianças (até 11 anos);

(iii) Com o intuito de verificar o cumprimento da Lei Municipal n. 349/2007, que dispõe sobre o número máximo de embarcações turísticas na zona de uso restrito da Refauts, foram realizados censos dessas embarcações nas enseadas dos Golfinhos e do Madeiro;

(iv) Para avaliação da rentabilidade do TOC na Refauts, realizou-se uma estimativa da receita mensal, registrando-se os seguintes dados: (a) valor do ingresso cobrado por passageiro, (b) número médio de passageiros pagantes (adultos) por embarcação e (c) número médio de passeios por dia. Da receita mensal estimada por embarcação descontou-se o valor da taxa turística arrecadada pelos proprietários de embarcação e destinada à Prefeitura Municipal de Tibau do Sul.

\subsection{ANÁLISE DE DADOS}

Para a análise dos dados, realizou-se a estatística descritiva, com os resultados sendo apresentados em porcentagem (frequência) ou valor médio. Como os dados obtidos neste estudo não apresentaram distribuição normal (Kolmogorov-Smirnov; $p>0,05$ ), o erro padrão é apresentado em associação ao valor médio das seguintes variáveis investigadas: (i) número de passeios por dia; (ii) duração média dos passeios; (iii) número médio de turistas por embarcação; (iv) número médio de embarcações saindo ou chegando da praia central de Pipa por classe de horário e (v) número médio de embarcações simultâneas nas enseadas dos Golfinhos e do Madeiro. Para o cálculo da estimativa da receita mensal (RM) por embarcação, obtida com o TOC na Refauts, usou-se a seguinte equação: RM = P x NT x NP x $\mathrm{ND}$, onde: P é o preço do ingresso em R\$̦; NT é o número médio de turistas pagantes por embarcação; NP é o número médio de passeios realizados por embarcação por dia e ND é o número de dias no mês em que a embarcação realizou passeio para a Refauts.

\section{RESULTADOS}

\subsection{DESCRIÇÃO DAS EMBARCAÇÕES TURÍSTICAS}

Foram registradas 11 embarcações licenciadas para observação de botos-cinza operando na Refauts, sendo classificadas em três tipos: lancha $(n=8)$, escuna $(n=2)$ e catamarã $(n=1)$. Os proprietários dessas embarcações são, em sua maioria, brasileiros, havendo sócios estrangeiros em apenas uma das embarcações turísticas. O ano de construção dessas embarcações variou de 1999 a 2013, a potência do motor de $115 \mathrm{hp} \mathrm{a} 225 \mathrm{hp}$ e de 4 a 8 cilindros, e a capacidade máxima, de 13 a 80 passageiros. Neste estudo, durante os 16 dias de amostragem, foram registrados 368 passeios. Nesses passeios, cinco das 11 embarcações avaliadas apresentaram número máximo de passageiros superior à capacidade estabelecida pelo fabricante da embarcação (Tabela 1). 
Tabela 1 - Descrição das embarcações turísticas para observação de botos-cinza, Sotalia guianensis, na Reserva Faunística Costeira de Tibau do Sul (Refauts), praia de Pipa, município de Tibau do Sul, RN, Brasil, de acordo com a capacidade máxima de passageiros por embarcação, ano de fabricação da embarcação e potência do motor. Os dados referentes a 368 passeios registrados em 16 dias de amostragem foram utilizados no cálculo do número máximo de passageiros por passeio e do número médio de passeios realizados por dia.

\begin{tabular}{lcccccc}
\hline Tipo & $\begin{array}{c}\text { Ano de } \\
\text { fabricação }\end{array}$ & $\begin{array}{c}\text { Potência } \\
\text { do motor }\end{array}$ & $\begin{array}{c}\text { Capacidade } \\
\text { máxima de } \\
\text { passageiros }\end{array}$ & $\begin{array}{c}\mathbf{N}^{\circ} \text { máximo de } \\
\text { passageiros/ } \\
\text { passeio }\end{array}$ & $\begin{array}{c}\mathbf{N}^{\circ} \text { total de } \\
\text { passeios } \\
\text { (n=368) }\end{array}$ & $\begin{array}{c}\mathbf{N}^{\circ} \text { médio de } \\
\text { passeios } \\
\text { realizados/dia ( } \mathbf{\pm} \text { EP) }\end{array}$ \\
\hline Lancha 1 & 2013 & $115 \mathrm{hp}$ & 13 & 15 & 53 & $3,3 \pm 0,4$ \\
Lancha 2 & 2009 & $150 \mathrm{hp}$ & 13 & 16 & 51 & $3,4 \pm 0,3$ \\
Lancha 3 & 2012 & $150 \mathrm{hp}$ & 15 & 16 & 52 & $3,5 \pm 0,3$ \\
Lancha 4 & 2013 & $200 \mathrm{hp}$ & 15 & 17 & 22 & $2,8 \pm 0,5$ \\
Lancha 5 & 2013 & $225 \mathrm{hp}$ & 16 & 15 & 24 & $3,4 \pm 0,4$ \\
Lancha 6 & 2013 & $200 \mathrm{hp}$ & 18 & 18 & 46 & $2,9 \pm 0,3$ \\
Lancha 7 & 2013 & $150 \mathrm{hp}$ & 18 & 21 & 42 & $2,8 \pm 0,3$ \\
Lancha 8 & 2011 & $150 \mathrm{hp}$ & 18 & 16 & 36 & $2,8 \pm 0,4$ \\
Escuna 1 & 1999 & 4 cilindros & 59 & 58 & 10 & $1,0 \pm 0,0$ \\
Catamarã & 2012 & 8 cilindros & 70 & 53 & 10 & $1,1 \pm 0,1$ \\
Escuna 2 & 2011 & 6 cilindros & 80 & 64 & 22 & $1,5 \pm 0,1$ \\
\hline
\end{tabular}

Fonte: Os autores.

\subsection{FREQUÊNCIA DE PASSEIOS PARA OBSERVAÇÃO DE BOTOS-CINZA}

Durante os 16 dias de amostragem e 368 passeios no total, registrou-se uma média ( \pm EP) de 23,0 \pm 2,4 passeios por dia com duração média ( $\pm \mathrm{EP}$ ) dos passeios de aproximadamente 50,0 $\pm 0,7 \mathrm{~min}$. Na Refauts, os passeios para observação de botos-cinza ocorreram entre $09 \mathrm{~h}$ e $16 \mathrm{~h}$, sofrendo pequenas alterações resultantes de variação de maré, nesses casos, iniciando-se após as 9h e terminando antes das 16h. Na praia central de Pipa, turistas de observação de botos-cinza foram mais frequentes entre $11 \mathrm{~h} 01$ - 11h30, com uma média total ( \pm EP) de 91,1 \pm 11,7 turistas embarcados e aproximadamente 4,6 \pm 0,5 embarcações saindo nessa classe de horário (Figura 2a). A chegada das embarcações à praia central de Pipa foi mais comum entre $12 \mathrm{~h} 01$ - 12h30, com aproximadamente 4,0 \pm 0,4 embarcações chegando nessa classe de horário (Figura 2b). Durante os 16 dias de amostragem, foram registrados no total 4.717 turistas nos passeios para observação de botos-cinza. Destes, 51\% dos turistas eram mulheres, $43 \%$ eram homens e $6 \%$ crianças (Tabela 2 ). 


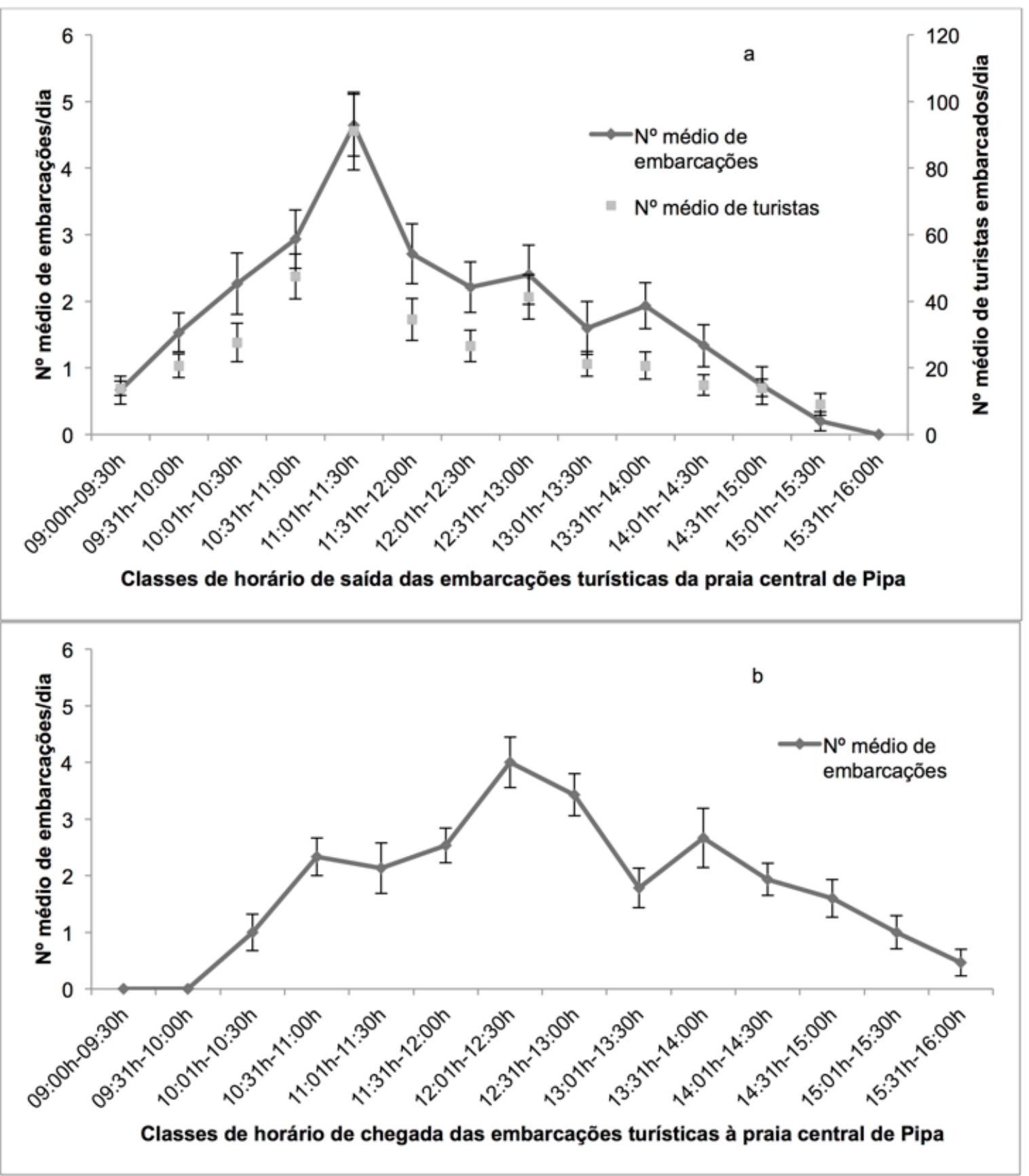

Figura 2 - Frequência de embarcações turísticas e de turistas de observação de botos-cinza, Sotalia guianensis, na Reserva Faunística Costeira de Tibau do Sul (Refauts), praia de Pipa, município de Tibau do Sul, RN, Brasil, de acordo com classes de horário de saída (a) e chegada (b) dessas embarcações na praia central de Pipa. Losangos representam número médio de embarcações/dia e barras representam erro padrão. Os dados foram calculados a partir do registro de 368 passeios em 16 dias de amostragem. 
Tabela 2 - Número total de turistas embarcados em 368 passeios para observação de botos-cinza, Sotalia guianensis, na Reserva Faunística Costeira de Tibau do Sul (Refauts), praia de Pipa, município de Tibau do Sul, RN, Brasil.

\begin{tabular}{|c|c|c|}
\hline & $\begin{array}{l}\mathrm{N}^{\circ} \text { total de turistas } \\
\text { amostrados }\end{array}$ & $\begin{array}{c}\mathrm{N}^{\circ} \text { médio de turistas } / \\
\text { passeio }( \pm E P)\end{array}$ \\
\hline Mulheres & 2425 & $6,6 \pm 0,3$ \\
\hline Homens & 2016 & $5,5 \pm 0,2$ \\
\hline Crianças (até 11 anos) & 276 & $0,8 \pm 0,1$ \\
\hline Total & 4717 & $12,8 \pm 0,5$ \\
\hline
\end{tabular}

Fonte: Os autores.

\subsection{NÚMERO MÁXIMO DE EMBARCAÇÕES NAS ENSEADAS DOS GOLFINHOS E DO MADEIRO}

Durante os censos realizados na enseada dos Golfinhos, foram registradas em média ( \pm EP) $2,1 \pm 0,1$ embarcações simultâneas para observação de botos-cinza. Na enseada do Madeiro, o número de embarcações simultâneas foi semelhante: 2,0 \pm 0,08 embarcações. Na enseada dos Golfinhos, em $35 \%$ dos registros, as embarcações não acataram o limite de apenas uma embarcação por vez nesta enseada, enquanto na enseada do Madeiro, o descumprimento à Lei Municipal n. 349/2007 ocorreu em 32,6\% dos registros. Vale destacar o registro de até sete embarcações simultâneas para observação de botos-cinza na enseada dos Golfinhos (Tabela 3).

Tabela 3 - Frequência de embarcações turísticas para observação de botos-cinza, baseada em 12 dias de amostragem, registrada simultaneamente entre $9 \mathrm{~h}$ e $16 \mathrm{~h}$ nas enseadas dos Golfinhos e do Madeiro, Reserva

Faunística Costeira de Tibau do Sul (Refauts), praia de Pipa, município de Tibau do Sul, RN, Brasil.

\begin{tabular}{|c|c|c|}
\hline \multirow{2}{*}{$\begin{array}{c}\text { Número de } \\
\text { embarcações }\end{array}$} & \multicolumn{2}{|c|}{ Frequência de embarcações turísticas } \\
\hline & $\begin{array}{c}\text { Enseada dos Golfinhos (\%) } \\
(n=266)\end{array}$ & $\begin{array}{c}\text { Enseada do Madeiro (\%) } \\
\qquad(n=269)\end{array}$ \\
\hline 0 & 41,7 & 40,9 \\
\hline 1 & 23,3 & 26,0 \\
\hline 2 & 16,2 & 15,2 \\
\hline 3 & 10,9 & 11,2 \\
\hline 4 & 4,9 & 4,8 \\
\hline 5 & 1,5 & 0,7 \\
\hline 6 & 1,1 & 0,7 \\
\hline 7 & 0,4 & 0,0 \\
\hline
\end{tabular}

Fonte: Os autores. 


\subsection{ESTIMATIVA DE RECEITA COM O TOC NA REFAUTS}

Na Refauts, os passeios para observação de botos-cinza ocorrem diariamente (de segunda-feira a domingo), durante todo o ano. Os preços dos passeios variaram de acordo com o tipo de embarcação. Em 2016, o passeio nas lanchas custou $R \$ 35,00$ e nas embarcações maiores, como catamarã e escuna, custou em torno de $\mathrm{R} \$ 40,00$. Tendo por base o valor de $\mathrm{R} \$ 35,00$ pago por cada turista, o lucro bruto mensal estimado para cada embarcação que levou 12 passageiros adultos por passeio (ver Tabela 2) e realizou 3 passeios ao dia (ver Tabela 1), foi de aproximadamente $R \$ 38.000,00$ ao mês/embarcação (R\$35,00 $\times 12$ pagantes $\times 3$ passeios/dia $\times 30$ dias). Vale salientar que, do lucro bruto mensal, é preciso subtrair a taxa turística da Refauts ( $\mathrm{R} \$ 1,60 /$ passageiro adulto - valor aplicado em 2016). Assim, obtémse uma estimativa de receita bruta de aproximadamente $\mathrm{R} \$ 36.000,00$ ao mês por embarcação. Desse valor final, se faz necessário subtrair ainda gastos com combustível, manutenção da embarcação, pagamento de salário dos mestres, contramestres, tratorista, pessoal de suporte (ajudantes de embarque) e vendedores de ingressos para o passeio.

\section{DISCUSSÃO}

\subsection{DESCRIÇÃO DAS EMBARCAÇÕES TURÍSTICAS}

Na Refauts, a estrutura para a realização dos passeios é composta por uma frota náutica relativamente nova, com a maior parte das embarcações tendo sido fabricada a partir de 2011. A equipe de apoio ao embarque e navegação também parece ser adequada, contando com ajudantes de embarque e mestre e contramestre de embarcação. Por outro lado, pela ausência de fiscalização efetiva, programa de monitoramento e de educação continuada para os operadores do TOC, uma parte significativa dos passeios realizados pelas embarcações licenciadas apresentou número de turistas acima da capacidade prevista pelo fabricante e órgãos reguladores. Essa inadequação pode resultar em prejuízos, tanto para o turista como para os condutores de embarcações.

Outro aspecto negativo tem sido a ausência de informação ambiental repassada ao turista antes, durante ou após os passeios, o que acarreta em perda de oportunidade para sensibilização ambiental dos turistas e ampliação do conhecimento destes sobre a Refauts. Estudos sobre a experiência dos turistas durante o TOC têm apontado que a maioria desses turistas espera um componente educacional durante os passeios e gostaria de saber mais informações sobre a fauna marinha local (LÜCK, 2003, 2015). Um estudo realizado na Refauts sobre a percepção dos mestres e contramestres (condutores) de embarcação também apontou que estes reconhecem a importância da conservação ambiental para a manutenção do TOC na região (SILVA et al., 2014).

\subsection{FREQUÊNCIA DE PASSEIOS PARA OBSERVAÇÃO DE BOTOS-CINZA}

Os passeios de barco realizados na Refauts tiveram duração relativamente curta, quando comparados aos passeios realizados em outras áreas de concentração de cetáceos no Brasil, a exemplo de Fernando de Noronha, PE, e Abrolhos, BA (Obs. Pess.). O fato de o passeio ter uma duração média de 50 min reduz o tempo de desconforto daqueles turistas que não se sentem bem com o movimento do mar e permite que condutores de embarcação realizem um número maior de passeios por dia. Por outro lado, mais barcos entrando e saindo das enseadas dos Golfinhos e do Madeiro emitirão mais ruídos, causados pelos motores das embarcações, o que pode acarretar em prejuízos para o boto-cinza (ALBUQUERQUE; SOUTO, 2013).

Neste estudo, também identificou-se a classe de horário de $11 \mathrm{~h}$ às $11 \mathrm{~h} 30$ como o intervalo com maior concentração de barcos e, consequentemente, de turistas, ao longo do dia. A identificação dessa classe de horário permitirá aos gestores da Reserva um direcionamento de esforços para o monitoramento do TOC e sensibilização ambiental dos turistas, no sentido de reduzir a pressão sobre os botos-cinza, alocando um maior número de funcionários e recursos para atender a essa demanda de maior fluxo turístico sem comprometer o bem-estar dos animais. 


\subsection{NÚMERO MÁXIMO DE EMBARCAÇÕES NAS ENSEADAS DOS GOLFINHOS E DO MADEIRO}

De acordo com a Lei Municipal n. 349/2007, que trata do transporte marítimo de visitação turística na Refauts, é permitida a presença de apenas uma embarcação turística ou recreativa por vez na zona de uso restrito da Refauts. Contudo, neste estudo, o número médio de embarcações simultâneas, registrado nesta zona, foi de aproximadamente duas embarcações, havendo inclusive registro de até sete embarcações simultâneas na enseada dos Golfinhos.

Essa inobservância quanto ao número simultâneo de embarcações em área de concentração de botoscinza já foi registrada por outros autores na área de estudo (ALBUQUERQUE; SOUTO, 2013; SANTOS JR. et al., 2006) e pode acarretar, em longo prazo, em prejuízos para esses animais, incluindo alterações comportamentais e redução do número de indivíduos nas áreas de ocorrência (ALBUQUERQUE; SOUTO, 2013; CARRERA et al., 2008).

Os efeitos do turismo de observação de cetáceos têm sido descritos em diversas áreas de concentração desses animais em todo o mundo (ARGÜELLES et al., 2016; PIROTTA et al., 2015; SANTOS JR. et al., 2006) e estão associados principalmente a alterações comportamentais. Por exemplo, um estudo realizado recentemente na Escócia apontou que o número de barcos turísticos simultâneos pode reduzir em até $49 \%$ as taxas de forrageamento de botos-da-tainha (PIROTTA et al., 2015), enquanto outro estudo realizado na Argentina apontou que a forma inapropriada de aproximação das embarcações turísticas pode afastar baleias-franca de sua área de concentração (ARGÜELLES et al., 2016). Estudos realizados na Refauts também apontaram alterações comportamentais em botos-cinza causadas por embarcações turísticas (CARRERA et al., 2008; SANTOS JR. et al., 2006; VALLE; MELO, 2006).

\subsection{ESTIMATIVA DE RECEITA COM O TOC NA REFAUTS}

O turismo de observação de botos-cinza na Refauts tem se destacado como uma importante fonte de renda para a comunidade da praia de Pipa, tendo em vista o número de turistas envolvidos diariamente nessa atividade e o valor arrecadado diretamente com a venda de ingressos para os passeios. Casos semelhantes têm sido observados, por exemplo, no Complexo Estuarino de Cananeia para observação de botos-cinza (FILLA et al., 2012) e no Parque Nacional de Anavilhanas para observação de boto-daAmazônia (ALVES et al., 2013). Na Refauts, durante 16 dias de amostragem, mais de 4.700 turistas realizaram o passeio de barco para observação de botos-cinza. Destes, aproximadamente $51 \%$ eram mulheres e $43 \%$ homens. Mulheres têm sido apontadas em outros estudos como público majoritário nas atividades de turismo de observação de cetáceos (FILBY et al., 2015; LÜCK, 2015; PARSONS et al., 2003) e essa informação pode ser útil no direcionamento de programas de gestão da Reserva, de forma a atender às necessidades intrínsecas ao público feminino.

Adicionalmente, a partir de uma estimativa da receita gerada por uma embarcação licenciada para atuar na Refauts durante um mês, detectamos que a atividade é lucrativa e que pode gerar no mínimo cinco empregos diretos (e.g., mestre, contramestre, tratorista, ajudante de embarque e vendedor de ingresso) e uma receita bruta de aproximadamente $\mathrm{R} \$ 36.000,00$ ao mês por embarcação. Hoyt e Iñíguez (2008) destacaram a contribuição vital do turismo de observação de cetáceos para o desenvolvimento das comunidades da América Latina, evidenciando uma elevada taxa anual de crescimento do TOC, cerca de 11,3\%. Outros estudos também apontaram a alta lucratividade do turismo de observação de cetáceos (CISNEROS-MONTEMAYOR et al., 2010; FILLA et al., 2012; HOYT; IÑÍGUEZ, 2008), o que evidencia a importância da conservação dessas espécies e de seus ecossistemas para a manutenção do TOC na região em longo prazo.

\section{CONSIDERAÇÕES FINAIS}

Como foi visto, embora a Refauts seja um importante destino turístico que vem gerando emprego e renda para a comunidade local, além de abrigar e ter como alvo turístico uma espécie de cetáceo ameaçada de extinção, a Reserva ainda não dispõe de um plano de manejo, nem de um programa de 
monitoramento e fiscalização das atividades turísticas dentro desta. A Refauts também não dispõe de controle de seus visitantes, nem possui servidores ou infraestrutura mínima como um centro de informações turísticas, banheiros ou lixeiras.

Os únicos servidores mantidos pela Prefeitura Municipal de Tibau do Sul na praia central de Pipa, registrados neste estudo, têm a função de controlar o número de turistas pagantes, com o intuito de garantir a arrecadação adequada da taxa turística da Refauts. Na ausência de um programa efetivo de monitoramento e gestão, os próprios operadores do turismo de observação de botoscinza, com a participação da Prefeitura Municipal de Tibau do Sul, vêm desenvolvendo uma tentativa de ordenamento, quanto ao cumprimento, mesmo que parcial, da Lei Municipal n. 349/2007. Recentemente, foi aplicado o método de Avaliação Rápida e Priorização da Gestão de Unidades de Conservação (Rappam) para identificar as fragilidades e fortalezas na implementação destas no Rio Grande do Norte, mas a Refauts não foi avaliada pelo método, devido à dificuldade de se contatar os gestores responsáveis pela Reserva.

Outro ponto que vale destacar é a necessidade de se aplicar de forma adequada os recursos arrecadados pela Rafauts. Dentre as possibilidades, como foram levantadas por alguns autores mencionados no decorrer do artigo, o valor arrecadado com a taxa turística poderia ser empregado para: o fechamento da área da Reserva, de forma a controlar o número de turistas; a construção de um pequeno centro de informações sobre a Reserva, de forma a promover a informação e sensibilização ambiental e para a infraestrutura das enseadas dos Golfinhos e do Madeiro (como a instalação de banheiros químicos e lixeiras), de forma a garantir infraestrutura mínima na Reserva. Um programa de monitoramento de atividades turísticas e de fluxo de embarcações também poderia ser implantado na Refauts, de forma a reduzir os efeitos do turismo sobre os botos-cinza.

Finalmente, um programa de educação continuada para os operadores e condutores do TOC viabilizaria uma gestão integrada e participativa da Refauts, tornando-os aliados no processo de conservação do boto-cinza. Para que as Unidades de Conservação possam atingir efetivamente seus objetivos, previstos no Sistema Nacional de Unidades de Conservação da Natureza - SNUC (BRASIL, 2000), será necessário, pelo menos: uma articulação das ações promovidas pelos diferentes atores sociais que integram a UC, integração dessas Unidades à economia local e o fortalecimento e implementação de seus planos de manejo.

Com o intuito de subsidiar o referido plano de manejo, sugere-se, ainda, que sejam avaliados, além dos aspectos analisados neste estudo, outros parâmetros sobre a conformidade das embarcações quanto à Lei Municipal n. 349/2007, em especial a velocidade máxima e o tipo de manobra das embarcações em distâncias inferiores a 100 m dos botos-cinza, nas zonas de uso restrito e controlado da Refauts.

\section{AGRADECIMENTOS}

Os autores são gratos aos operadores de turismo, mestres e contramestres de embarcações licenciadas para a Refauts e à Prefeitura Municipal de Tibau do Sul pelas informações fornecidas e colaboração durante a realização deste estudo. Os autores agradecem também aos dois revisores anônimos pelos valiosos comentários que contribuíram para a melhoria da qualidade desse artigo.

\section{REFERÊNCIAS}

AGARDY, M. Accommodating ecotourism in multiple use planning of coastal and marine protected areas. Ocean \& Coastal Management, v. 20, n. 3, p. 219-239, 1993.

ALBUQUERQUE, N. D. S.; SOUTO, A. D. S. Motorboat noise can potentially mask the whistle sound of estuarine dolphins (Sotalia guianensis). Ethnobiology and Conservation, v. 2, 2013. Disponível em: http://ethnobioconservation.com/index.php/ebc/article/view/26/97. Acesso em: nov. 2016. 
ALMEIDA JR., E. B.; ZICKEL, C. S. Fisionomia psamófila-reptante: riqueza e composição de espécies na praia da Pipa, Rio Grande do Norte, Brasil. Pesquisas, Botânica, v. 60, p. 289-299, 2009.

ALVES, L. C. P. S. et al. As atividades turísticas baseadas na alimentação artificial de botos-da-Amazônia (Inia geoffrensis) e a legislação brasileira. Desenvolvimento e Meio Ambiente, v. 28, p. 89-106, 2013.

ARAÚJO, J. P.; PASSAVANTE, J. Z. O.; SOUTO, A. S. Behavior of the estuarine dolphin, Sotalia guianensis, at Dolphin Bay, Pipa, Rio Grande do Norte, Brazil. Tropical Oceanography, v. 29, n. 2, p. 13-23, 2001.

ARGÜELLES, M. B. et al. Tourism management perspectives. Tourism Management, v. 18, p. 118-124, 2016.

BARROS, N. B. Recent cetacean records for southeastern Brazil. Marine Mammal Science, v. 7, n. 3, p. 296-306, 1991.

BOROBIA, M. et al. Distribution of the South American dolphin Sotalia fluviatilis. Canadian Journal of Zoology, v. 69, n. 4, p. 1025-1039, 1991.

BRASIL. Lei Federal n. 9.985, de 18 de julho de 2000. Institui o Sistema Nacional de Unidades de Conservação da Natureza e dá outras providências. Diário Oficial [da] República Federativa do Brasil, Poder Executivo, Brasília, DF, 19 jul.

CAMPOS, D. F.; MAIA, D. N. B. Qualidade dos serviços turísticos no destino Pipa/Brasil: um estudo sob a ótica de uma análise de cluster. Revista Brasileira de Pesquisa em Turismo, v. 9, n. 2, p. 258-277, 2015.

CARR, T.; BONDE, R. K. Tucuxi (Sotalia fluviatilis) occurs in Nicaragua, $800 \mathrm{~km}$ of its previously known range. Marine Mammal Science, v. 16, n. 2, p. 447-452, 2000.

CARREGOSA, E. A.; SILVA, S. L. C.; KUNHAVALIK, J. P. Unidade de Conservação e comunidade local: uma relação em construção. Desenvolvimento e Meio Ambiente, v. 35, p. 305-319, 2015.

CARRERA, M. L.; FAVARO, E. G. P.; SOUTO, A. The response of marine tucuxis (Sotalia fluviatilis) towards tourist boats involves avoidance behaviour and a reduction in foraging. Animal Welfare, v. 17, n. 2, p. 117-123, 2008.

CISNEROS-MONTEMAYOR, A. M. et al. The global potential for whale watching. Marine Policy, v. 34, n. 1 , p. $1273-1278,2010$.

DIAMANTIS, D. The concept of ecotourism: evolution and trends. Current Issues in Tourism, v. 2, n. 2-3, p. 93-122, 1999.

FILBY, N. E.; STOCKIN, K. A.; SCARPACI, C. Social science as a vehicle to improve dolphin-swim tour operation compliance? Marine Policy, v. 51, p. 40-47, 2015.

FILLA, G. F. et al. The economic evaluation of estuarine dolphin (Sotalia guianensis) watching tourism in the Cananeia region, south-eastern Brazil. International Journal of Green Economics, v. 6, n. 1, p. 95-116, 2012.

FLORES, P. A. C. Preliminary results of a photoidentification study of the marine tucuxi, Sotalia fluviatilis, in southern Brazil. Marine Mammal Science, v. 15, n. 3, p. 840-847, 1999.

GOODWIN, H. In pursuit of ecotourism. Biodiversity \& Conservation, v. 5, n. 3, p. 277-291, 1996.

HOYT, E. Whale watching 2001: worldwide tourism numbers, expenditures, and expanding socioeconomic benefits. International Fund for Animal Welfare (IFAW), Yarmouth Port, USA, 2001. 164 p. Disponível em: <http://www.ifaw.org/sites/default/files/whale\%20watching\%202001.pdf>. Acesso em: 20 nov. 2014. 
HOYT, E.; IÑIGUEZ, M. The state of whale watching in Latin America. WDCS. Chippenham, UK; IFAW, East Falmouth, EEUU; e Global Ocean, Londres, 2008. 60p. Disponível em: <http://uk.whales.org/sites/ default/files/whale-watching-latin-america.pdf>. Acesso em: 23 ago. 2015.

INSTITUTO NACIONAL DE METEOROLOGIA. Banco de Dados Meteorológicos para Ensino e Pesquisa (BDMEP), 2015. Disponível em: <http://www.inmet.gov.br/portal/index.php?r=bdmep/bdmep>. Acesso em: 20 jul. 2015.

LÜCK, M. Education on marine mammal tours as agent for conservation - but do tourists want to be educated? Ocean \& Coastal Management, v. 46, n. 9, p. 943-956, 2003.

Education on marine mammal tours - but what do tourists want to learn? Ocean \& Coastal Management, v. 103, p. 25-33, 2015.

LUNARDI, D. G.; FERREIRA, R. G. Group composition influences on behavioral sequence patterns of the Guiana dolphin Sotalia guianensis. Journal of Ethology, v. 31, n. 1, p. 49-53, 2013.

Fission-fusion dynamics of Guiana dolphin (Sotalia guianensis) groups at Pipa Bay, Rio Grande do Norte, Brazil. Marine Mammal Science, v. 30, n. 4, p. 1401-1416, 2014.

MAGANHOTTO, R. F. et al. Unidades de Conservação: limitações e contribuições para a conservação da natureza. Sustentabilidade em Debate, v. 5, n. 3, p. 203-221, 2014.

NASCIMENTO, L. F.; MEDEIROS, P. I. A. P.; YAMAMOTO, M. E. Descrição do comportamento de superfície do boto-cinza, Sotalia guianensis, na Praia de Pipa-RN. Psicologia: reflexão e crítica, v. 21, n. 3, p. 509517, 2008.

PACHECO, G. H. S.; FREITAS NETO, O.; SEVERO, R. N. F. Análise da estabilidade das falésias de Tibau do Sul por métodos de equilíbrio-limite. Holos, v. 2, p. 78-100, 2006.

PANSARD, K. C. A. et al. Feeding ecology of the estuarine dolphin (Sotalia guianensis) on the coast of Rio Grande do Norte, Brazil. Marine Mammal Science, v. 27, n. 4, p. 673-687, 2011.

PARSONS, E. C. M. et al. Whale-watching tourists in West Scotland. Journal of Ecotourism, v. 2, n. 2, p. 93-113, 2003.

PIROTTA, E. et al. Quantifying the effect of boat disturbance on bottlenose dolphin foraging activity. Biological Conservation, v. 181, p. 82-89, 2015.

ROSSI-SANTOS, M. R.; FLORES, P. A. C. Feeding strategies of the Guiana dolphin Sotalia guianensis. Open Marine Biology Journal, v. 3, p. 70-76, 2009.

SANTOS JR., E. et al. Behavior of estuarine dolphin, Sotalia guianensis (Van Bénédén) (Cetacea, Delphinidae) in the presence of tourist boats in Pipa Beach, Rio Grande do Norte, Brazil. Revista Brasileira de Zoologia, v. 23, n. 3, p. 661-666, 2006.

SILVA, L. A. F. et al. Turismo de observação de cetáceos no litoral sul do Rio Grande do Norte, Brasil. Revista Turismo \& Desenvolvimento, v. 21, n. 4, p. 423-436, 2014.

SPINELLI, L. H. P.; NASCIMENTO, L. F.; YAMAMOTO, M. E. Identificação e descrição da brincadeira em uma espécie pouco estudada, o boto-cinza (Sotalia fluviatilis), em seu ambiente natural. Estudos de Psicologia, v. 7, n. 1, p. 165-171, 2002.

TEIXEIRA, M. G.; VENTICINQUE, E. M. Fortalezas e fragilidades do sistema de Unidades de Conservação potiguar. Desenvolvimento e Meio Ambiente, v. 29, p. 113-126, 2014.

TIBAU DO SUL. Decreto n. 14, de 17 de fevereiro de 2006. Dispõe sobre a criação da Reserva Faunística Costeira de Tibau do Sul - Refauts, e dá outras providências. Diário Oficial [da] Prefeitura de Tibau do Sul, Poder Executivo, Tibau do Sul, RN, 17 fev. 2006. 
Lei Municipal n. 349, de 28 de dezembro de 2007. Dispõe sobre o transporte marítimo de visitação turística no âmbito da Reserva Faunística Costeira de Tibau do Sul - Refauts, e dá outras providências. Diário Oficial [da] Prefeitura de Tibau do Sul, Poder Executivo, Tibau do Sul, RN, 28 dez. 2007.

TORQUEBIAU, E.; TAYLOR, R. Natural resource management by rural citizens in developing countries: innovations still required. Biodiversity and Conservation, v. 18, n. 10, p. 2537-2550, 2009.

VALLE, A. L.; MELO, F. C. C. Alterações comportamentais do golfinho Sotalia guianensis (Gervais, 1953) provocadas por embarcações. Biotemas, v. 19, n. 1, p. 75-80, 2006.

WILSON, C.; TISDELL, C. Conservation and economic benefits of wildlife-based marine tourism: sea turtles and whales as case studies. Human Dimensions of Wildlife, v. 8, n. 1, p. 49-58, 2003. 